\title{
The status and model of children primary nephrotic syndrome in continuing nursing
}

\author{
Feng Xia Li ${ }^{1,2}$, Ya Li Hou ${ }^{3,4}$, Li Sha Zhou ${ }^{1,2}$, Yan Dong ${ }^{1,2}$, Jing Wen Zhao ${ }^{1,2}$, Zhen Xiang Li $^{5,6}$ \\ ${ }^{1}$ Department of Pediatric Nephropathy and Rheumatism Immunology, Shandong Provincial Hospital Affiliated to Shandong First Medical \\ University, Jinan, China; ${ }^{2}$ Department of Pediatric Nephropathy and Rheumatism Immunology, Shandong Provincial Hospital Affiliated to \\ Shandong University, Jinan, China; ${ }^{3}$ Department of Stomatology, Shandong Provincial Hospital Affiliated to Shandong First Medical University, \\ Jinan, China; ${ }^{4}$ Department of Stomatology, Shandong Provincial Hospital Affiliated to Shandong University, Jinan, China; ${ }^{5}$ Department of \\ Outpatient, Shandong Provincial Hospital Affiliated to Shandong First Medical University, Jinan, China; ${ }^{6}$ Department of Outpatient, Shandong \\ Provincial Hospital Affiliated to Shandong University, Jinan, China \\ Contributions: (I) Conception and design: FX Li; (II) Administrative support: ZX Li; (III) Provision of study materials or patients: FX Li; (IV) \\ Collection and assembly of data: Y Dong, LS Zhou, JW Zhao; (V) Data analysis and interpretation: YL Hou; (VI) Manuscript writing: All authors; (VII) \\ Final approval of manuscript: All authors. \\ Correspondence to: Zhen Xiang Li. Department of Outpatient, Shandong Provincial Hospital Affiliated to Shandong First Medical University, Jinan, \\ China; Department of Outpatient, Shandong Provincial Hospital Affiliated to Shandong University, No. 324 Jingwu Street, Huaiyin District, Jinan \\ 250021, China. Email: lizhenxiang981@163.com.
}

Background Nephrotic syndrome (NS) is a common glomerular disease in children. Nursing during hospitalization alone cannot solve the psychological, physiological and social health problems of children. Continuing care models may provide patients with more continuous and efficient care services. Therefore, the present study aimed to provide theoretical support for the implementation and development of children's primary nephrotic syndrome (PNS) and children's chronic disease continuing nursing through the construction of a children's PNS continuing nursing model.

Methods: Each item of the transitional care model for children with PNS was demonstrated using the Delphi method for two rounds of correspondence. The main items included four components: the composition of personnel, the responsibilities of each member, the content of work, and the evaluation indicators.

Results: A transitional care model for children with PNS was formed. The expert judgment coefficient of two rounds of correspondence was 0.84 , the familiarity degree coefficient was 0.76 , the authority degree coefficient was 0.80 , the coefficient of variation was between 0.02 and 0.23 , and the coordination coefficient was 0.458 and 0.327 , respectively $(\mathrm{P}<0.01)$.

Conclusions: The experts in the present research were highly motivated, had a high degree of authority, and presented consistent opinions. Hence, the construction of a transitional care model for children with PNS is scientifically feasible.

Keywords: Transitional care; Delphi; children with primary nephrotic syndrome (children with PNS); construction of model; nursing

Submitted Nov 11, 2019. Accepted for publication Aug 18, 2020.

doi: 10.21037/apm-19-480

View this article at: http://dx.doi.org/10.21037/apm-19-480

\section{Introduction}

Nephrotic syndrome (NS) (1) is a clinical syndrome, in which a large number of plasma proteins are lost from urine due to the increase in permeability of the glomerular filtration membrane and a series of pathophysiological 
changes. NS is primarily characterized by massive proteinuria, hypoalbuminemia, hyperlipidemia and edema. Furthermore, NS is generally divided into primary NS (PNS), secondary NS and congenital NS. PNS accounts for $90 \%$ (2) of the total number of NS cases in children. Hence, it is a common glomerular disease in children. Nursing during hospitalization alone cannot solve the psychological, physiological and social health problems of children. It has been generally considered that continuing care refers to a series of measures and activities that start before the patient is discharged from the hospital. The aim is to strengthen the coordination and continuity of health care. Furthermore, the highest goal of continuing care is to smoothly and safely transfer patients from the hospital to the family or community, in order to improve their postdischarge outcome (3).

Recently, foreign literatures have revealed that continuing care can effectively improve the quality of life of patients, reduce medical expenses and reduce the rate of readmission, thereby achieving the purpose of the rational use of medical resources $(4,5)$. More mature nursing models abroad have been repeatedly applied in clinic, and the results have shown that these continuing care models can provide patients with more continuous and efficient care services (6). Tang et al. (7) reported that China's continuing care remains in the primary development stage, there is no mature theoretical system and continuing care mode, and there is a lack of continuing care research on children's chronic diseases.

Therefore, the present study was conducted by using the Delphi method to construct a continuing nursing model for children with PNS, providing a mature, scientific and feasible continuing care model for children with PNS, and a reference for the management of chronic diseases in children and chronic diseases in all populations. We present the following article in accordance with the STROBE Reporting Checklist (available at http://dx.doi. org/10.21037/apm-19-480).

\section{Methods}

\section{Establishment of the research group}

The research team consisted of one professor of nursing, one associate professor of nursing, and four supervisor nurses. The research team was responsible for reviewing the expert correspondence questionnaire, selecting Delphi experts, and completing the data analysis. This study was conducted in accordance with the Declaration of Helsinki (as revised in 2013) and approved by the ethics committee of Biomedical Research Ethic Committee of Shandong Provincial Hospital (No. SWYX2020-044). All guardians had signed the informed consent.

\section{Inclusion criteria}

The inclusion criteria for the research group of experts were as follows: (I) experts with more than 10 years of clinical nursing work; (II) experts with a bachelor's degree or above; (III) experts with a supervisor nurse position or above; (IV) experts who volunteered to participate in the present study.

In conducting the Delphi inquiry, the number of experts were controlled at 15-50 experts (8). The subject selected 43 experts from the children's nephropathy nursing field in Third Grade Class A hospitals in Shandong, Shanghai, Beijing, Hebei, Yunnan, Guizhou, Jiangsu and other provinces, pediatric chronic disease nursing, and pediatric nursing management. The inclusion criteria for determining the correspondence experts were as follows: (I) experts with a bachelor degree or above, and experts with an intermediate professional title or above; (II) experts who have performed continuing care in a department or hospital; (III) experts engaged in children's nephropathy or pediatric chronic disease nursing, or pediatric nursing management for more than 10 years in Third Grade Class A hospitals; (IV) experts who volunteered to participate in the present study.

\section{Delphi expert inquiry process}

In October 2017, through a questionnaire survey, 43 questionnaires were distributed, and 41 questionnaires were collected. After the first round of expert correspondence was completed, the validity of all questionnaires was assessed. Then, the data of the questionnaire was summarized and statistically analyzed. According to the principles of the mean value assigned by an importance of $>3.5$, a standard deviation of $<1$ and a coefficient of variation of $<0.25$, each item was screened. Then, combined with the suggestions and opinions provided by the experts, some parts were modified and adjusted to form a second round of expert letter. In November 2017, 41 questionnaires were distributed and collected. The second round of expert opinions were basically the same, and the investigation was completed. 
Table 1 General information sheet for experts $(n=41)$

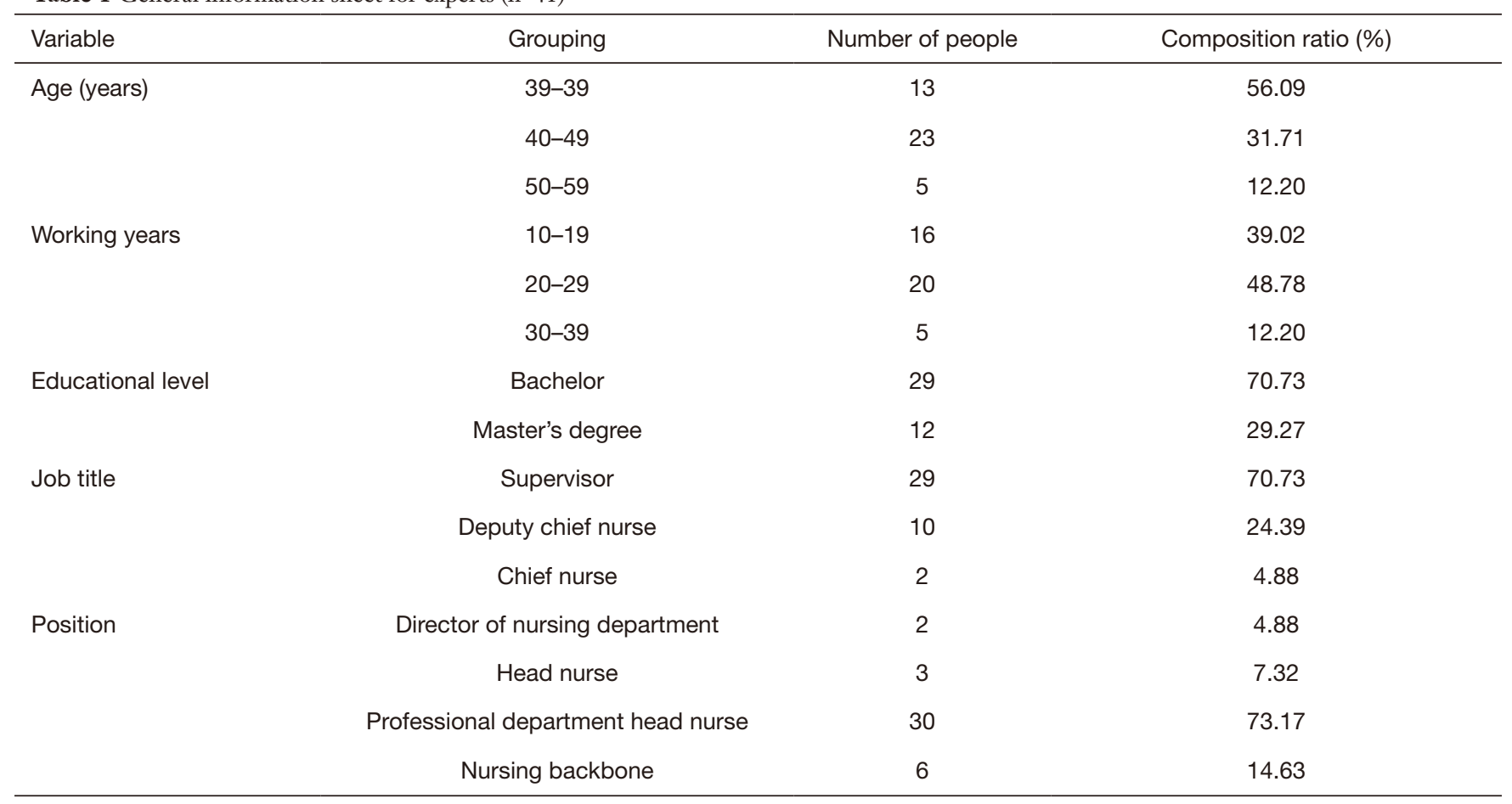

\section{Investigation of the expert correspondence questionnaire}

Based on the results of the literature search, and combined with the clinical experience and discussion results of the research team, the framework of the continuing care model for children with PNS was preliminarily constructed, which included the composition of the staff, the duties of each member, the work content of the continuing care model, and the effect evaluation. This consisted of four first-level entries, 20 second-level entries, 23 third-level entries, and 36 four-level entries, thereby forming the first round of expert letters.

\section{Statistical methods}

SPSS 22.0 (IBM, Chicago, USA) was used to analyze the mean, standard deviation, coefficient of variation, authority degree coefficient, Kendall harmony coefficient and questionnaire recovery rate.

\section{Results}

\section{Analysis of the basic situation of the experts}

The 41 nursing experts who completed the study were distributed in pediatric clinical nursing or pediatric nursing management positions in 13 large Third Grade Class A hospitals in seven provinces and cities in China. The average working life of these experts was 20.92 years. Furthermore, their clinical and management experience of pediatric nursing was rich, and their highest degree was undergraduate and above, in which $29.27 \%$ were master's degree holders, $>29.27 \%$ were deputy chief nurses, $70.73 \%$ were supervisors, and $85.37 \%$ were experts who held administrative positions (Table 1).

\section{Correspondence expert enthusiasm analysis}

In the first round of enquiries, 43 questionnaires were distributed. A total of 41 experts completed the questionnaires, in which 41 questionnaires were valid, and the effective questionnaire recovery rate was $95.35 \%$. The second round of consultations issued 41 questionnaires, and 41 experts completed the questionnaires. All 41 questionnaires were valid, and the effective questionnaire recovery rate was $100 \%$, indicating that the experts have a high degree of participation on this topic. At the same time, in the first round of enquiries, 12 experts proposed 14 amendments. In the second round of enquiries, one expert 
Table 2 Expert coordination coefficient and significance test $(\mathrm{n}=41)$

\begin{tabular}{lcccc}
\hline Project & W & $\chi^{2}$ & df & P \\
\hline Round 1 entry & 0.458 & 33.732 & 3 & $<0.01$ \\
Round 2 entry & 0.327 & 93.257 & 20 & $<0.01$ \\
\hline
\end{tabular}

proposed adjustment opinions. During the consultation process, these experts also contacted the research team through WeChat, telephone, etc. This ensured the consistency of understanding of some of the concepts and items, fully demonstrating that these experts have high enthusiasm for the research of this topic.

\section{Authoritative analysis of experts}

In the Delphi expert's letter of inquiry, the authoritativeness of the expert was expressed by the authority $(\mathrm{Cr})$ of the expert. Usually, the expert's judgment coefficient $(\mathrm{Ca})$ was used to represent the expert's judgment. Furthermore, the expert's familiarity coefficient (Cs) represents the familiarity of the expert, and $\mathrm{Cr}$ was analyzed through the $\mathrm{Ca}$ and Cs. The basis for the expert's judgment was based on practical experience, relevant theoretical analysis, references to relevant domestic and foreign materials, and the intuitive judgment of the four items. The degree of familiarity of correspondence consultation experts was assigned to five levels: familiar, a little familiar, general, not too familiar, and not familiar (9). $\mathrm{Cr}=(\mathrm{Ca}+\mathrm{Cs}) / 2(10)$. If $\mathrm{Cr}$ was $>0.7$, it was generally considered that the expert's degree of authority is relatively high in this letter. By calculation, $\mathrm{Ca}=0.84$, $\mathrm{Cs}=0.76, \mathrm{Cr}=(\mathrm{Ca}+\mathrm{Cs}) / 2$. The expert's authoritative coefficient was 0.80 , which was greater than 0.7 , indicating that in the present study, the authority of these experts was relatively high.

\section{Analysis of the degree of coordination of experts}

In general, the indicator indicating the degree of coordination of expert opinions is the Kendall's coordination coefficient $W$, and the $W$ value should be between 0 and 1 . The value of $W$ is the degree of coordination of the letter of inquiry to the expert. The $W$ value and its significance test were performed to verify the degree of coordination of the $M$ indicators or items through these $\mathrm{N}$-accounting experts (11). After completing two rounds of expert consultations, the Kendall's coordination coefficient was 0.458 and 0.327 , respectively.
The significance test revealed that $\mathrm{P}<0.01$, and the difference was statistically significant (Table 2). After the second round of letters, the index coefficient of variation was $<0.25$, indicating that the reliability and coordination of these expert opinions were better.

\section{Expert consultation results}

In the first round of enquiries, 12 experts put forward 14 opinions and suggestions on the continuing care model and evaluation indicators of children with PNS. Through discussion in the group, the review of the literature and combining these opinions, 13 amendments were adopted, while one amendment was not adopted. Finally, one secondary entry, seven tertiary entries and three four-level entries were added, one secondary entry was adjusted, and two tertiary entries and six four levels of entries were adjusted and modified. The revised letter query volume included the composition of the personnel, the responsibilities of each member, the work content of the continuation of the care model, and the evaluation index of the effect. There were four level 1 entries, 21 secondary entries, 30 tertiary entries, and 36 four-level entries in the second round of expert correspondence (Tables 3-6).

\section{Discussion}

The outcomes of the present study revealed that a transitional care model for children with PNS was formed. The expert judgment coefficient of two rounds of correspondence was 0.84 , the familiarity degree coefficient was 0.76 , the authority degree coefficient was 0.80 , the coefficient of variation was between 0.02 and 0.23 , and the coordination coefficient was 0.458 and 0.327 , respectively.

\section{Reliability analysis of the construction of the continuing care model for children with PNS}

The Delphi method, which is also known as the Expert Consultation Method (12), mainly entails the sending of letters to experts in various forms, the summarization of opinions and statistical analyses of each expert, and the conduction of several rounds of anonymous expert letters. Until the opinions of these experts in the letter basically converge, the inquiries would eventually form a reliable model. The Delphi method has been widely used in clinical nursing research since the 1970s. After the anonymous selection of experienced, authoritative and academically- 
Table 3 Child primary nephrotic syndrome continuation nursing model personnel composition

\begin{tabular}{|c|c|c|c|}
\hline Items & Mean (score) & $\begin{array}{l}\text { Standard } \\
\text { deviation }\end{array}$ & $\begin{array}{c}\text { Coefficient of } \\
\text { variation }\end{array}$ \\
\hline Child primary nephrotic syndrome continuation nursing model personnel composition & 4.85 & 0.42 & 0.09 \\
\hline Professional nurses (supervisors and above) & 4.85 & 0.42 & 0.09 \\
\hline Dietitian & 4.61 & 0.63 & 0.14 \\
\hline Pharmacist & 4.37 & 0.83 & 0.19 \\
\hline Counselor & 4.32 & 0.82 & 0.19 \\
\hline
\end{tabular}

recognized nursing experts, each letter-inquiring expert independently completes the letter query volume. The results of the letter inquiry volume can effectively and truthfully reflect the opinions of these experts. This topic was based on the construction procedure of the Delphi expert correspondence method, in order to construct a continuing care model for children with PNS. The key to Delphi's success is the choice of experts (13). The results of the present study included the general information of nursing experts, effective questionnaire recovery rate, expert authority coefficient, coefficient of variation, and coordination coefficient $(\mathrm{P}<0.01)$, exhibiting strong coordination and reliability.

\section{Feasibility analysis of the construction of the continuing care model for children with PNS}

Studies have revealed that the increase in continuing care can improve not only the level of medical services and work efficiency, but also patient satisfaction, making an important contribution to the realization of quality care (14). According to a survey study (15), most of the discharged patients have guidance needs for the behavior of the disease, disease knowledge, treatment plan, and home care during the home care process. However, these needs are difficult to meet. At present, in China, regardless of whether it is an adult patient or child patient, the continuing care after discharge is generally completed by a part-time professional nurse in the hospital. However, the continuing care lacks unified modes, standards and procedures, and lacks a fulltime and professional team.

In the present study, the Delphi method was used to construct the continuing care model for children with PNS. The nurses, professional nurses (supervisors and above), assistant nurses, doctors, dieticians, pharmacists and psychologists were established. The multidisciplinary continuing care team within the team determined the responsibilities of each member of the team, starting with file establishment, pre-discharge assessment and home care guidance, the basic information of the child, medication compliance, laboratory indicators, infection status and other complications, and other aspects of the assessment, the planned nursing knowledge, condition observation, lifestyle, review time, follow-up precautions and other home carerelated knowledge missions and guidance for the children and parents, to the outpatient follow-up after discharge. The telephone follow-up was alternated, the telephone Q\&A was synchronized with the WeChat Q\&A, and the knowledge of the disease was continuously delivered. Hence, the workflow and work content of the continuation of care were established, and the effect evaluation index was unified. This model can help discharged children obtain professional and continuous long-lasting medical care. Therefore, the continuing nursing mode of children with PNS adapts to the development of modern medical nursing technology and models.

\section{It is of great significance to construct a continuing care model for children with PNS}

In foreign countries, nursing experts have taken the lead in the United States, and actively determined how to improve their quality of life and treatment compliance with chronic diseases (16). Most of the continuing care is 
Table 4 Children's primary nephrotic syndrome in the continuing nursing model

\begin{tabular}{|c|c|c|c|}
\hline Items & $\begin{array}{c}\text { Mean } \\
\text { (score) }\end{array}$ & $\begin{array}{l}\text { Standard } \\
\text { deviation }\end{array}$ & $\begin{array}{l}\text { Coefficient of } \\
\text { variation }\end{array}$ \\
\hline Children's primary nephrotic syndrome in the continuing nursing model & 4.66 & 0.53 & 0.11 \\
\hline Coordinating arrangements for continuing nursing work & 4.80 & 0.40 & 0.08 \\
\hline Professional nurse duties & 4.85 & 0.36 & 0.07 \\
\hline $\begin{array}{l}\text { Responsible for data analysis and implementation and revision of corresponding continuing } \\
\text { care measures }\end{array}$ & 4.85 & 0.36 & 0.07 \\
\hline Maintenance of WeChat public platform information & 4.54 & 0.60 & 0.13 \\
\hline Complete home follow-up & 4.32 & 0.91 & 0.21 \\
\hline Auxiliary nurse duties & 4.37 & 0.99 & 0.23 \\
\hline Complete telephone follow-up & 4.37 & 0.99 & 0.23 \\
\hline Auxiliary completion of the implementation of continuous care measures & 4.44 & 0.67 & 0.15 \\
\hline Auxiliary completion of the collection and sorting of related materials & 4.44 & 0.67 & 0.15 \\
\hline Supervisor duties & 4.78 & 0.42 & 0.09 \\
\hline Participation in the revision of the continuation care program & 4.78 & 0.42 & 0.09 \\
\hline Pharmacist duties & 4.56 & 0.67 & 0.15 \\
\hline Provide guidance and $Q$ \& $A$ on drug related aspects & 4.56 & 0.67 & 0.15 \\
\hline Participate in the development of drug treatment plan for discharge & 4.59 & 0.63 & 0.14 \\
\hline Counselor duties & 4.41 & 0.74 & 0.17 \\
\hline Providing psychological counseling and counseling to children and parents & 4.42 & 0.74 & 0.17 \\
\hline $\begin{array}{l}\text { Participate in assessing the psychological status of children and parents when they are } \\
\text { discharged from hospital }\end{array}$ & 4.39 & 0.74 & 0.17 \\
\hline
\end{tabular}

carried out by multidisciplinary teams, including advanced practice nurse (APN), doctors, social workers, rehabilitation therapists, etc. Among them, APN plays a leading role in the implementation of continuing care $(17,18)$.

Some of the more mature nursing models have been applied in clinic for a number of times, and the results have revealed that these extended care models can provide patients with more continuous and efficient care services (6).

Tang et al. (7) reported that continuing care in China remains in the primary development stage. At present, the 
Table 5 Children's primary nephrotic syndrome continued care mode work content

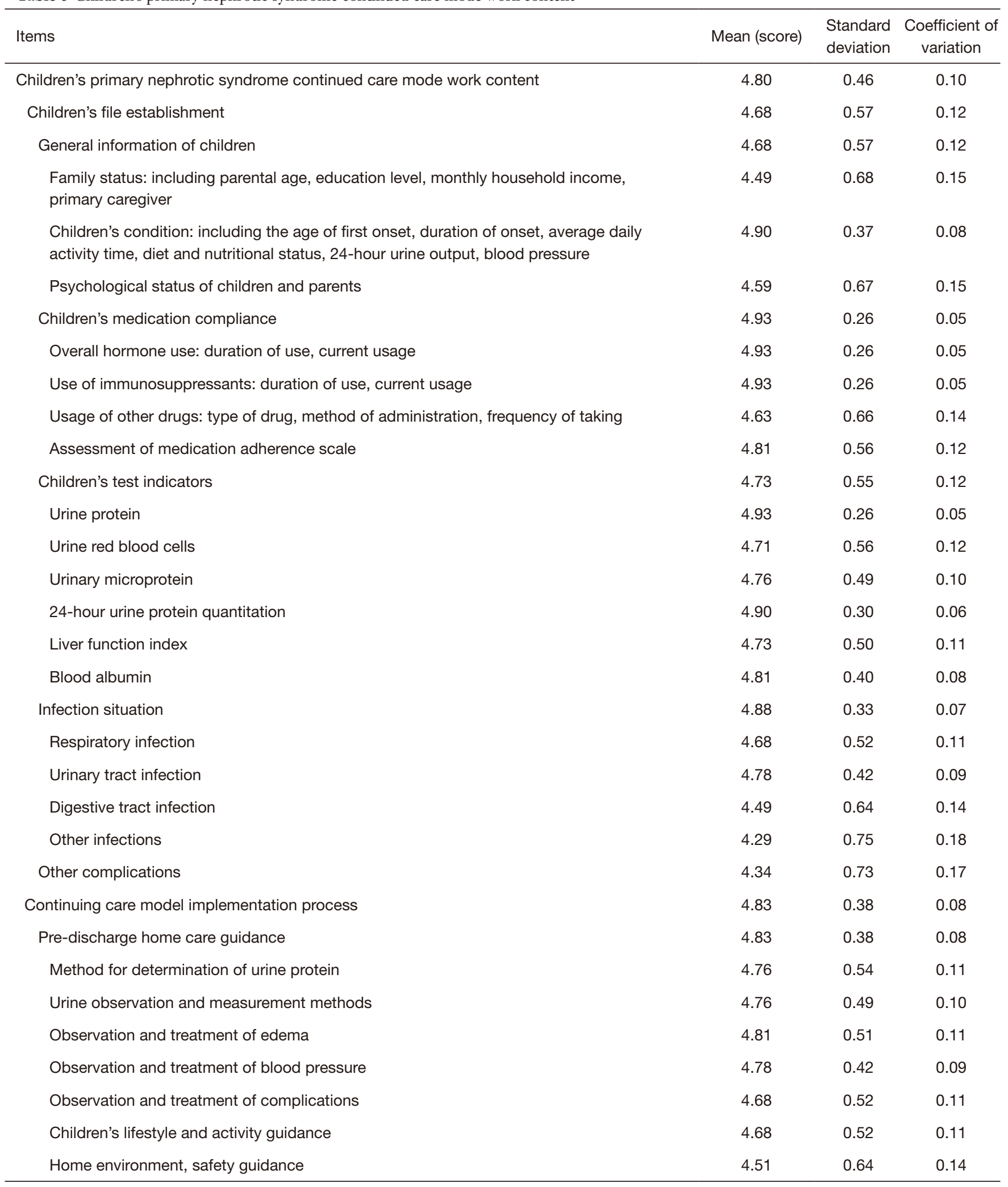

Table 5 (continued) 
Table 5 (continued)

\begin{tabular}{|c|c|c|c|}
\hline Items & Mean (score) & $\begin{array}{l}\text { Standard } \\
\text { deviation }\end{array}$ & $\begin{array}{c}\text { Coefficient of } \\
\text { variation }\end{array}$ \\
\hline Outpatient appointment method & 4.29 & 0.75 & 0.18 \\
\hline Home care guidance on the day of discharge & 4.61 & 0.59 & 0.13 \\
\hline Vaccination precautions & 4.56 & 0.59 & 0.13 \\
\hline Follow-up call and frequency notification & 4.49 & 0.71 & 0.16 \\
\hline Continuation of care after discharge & 4.71 & 0.56 & 0.12 \\
\hline 24-hour telephone answer & 4.15 & 0.85 & 0.21 \\
\hline WeChat group 8am-8pm for online Q \& A & 4.42 & 0.63 & 0.14 \\
\hline WeChat public account release related nursing knowledge & 4.32 & 0.72 & 0.17 \\
\hline Family visits for special children & 4.44 & 0.63 & 0.14 \\
\hline
\end{tabular}

Table 6 Children with primary nephrotic syndrome extended care model effect evaluation index

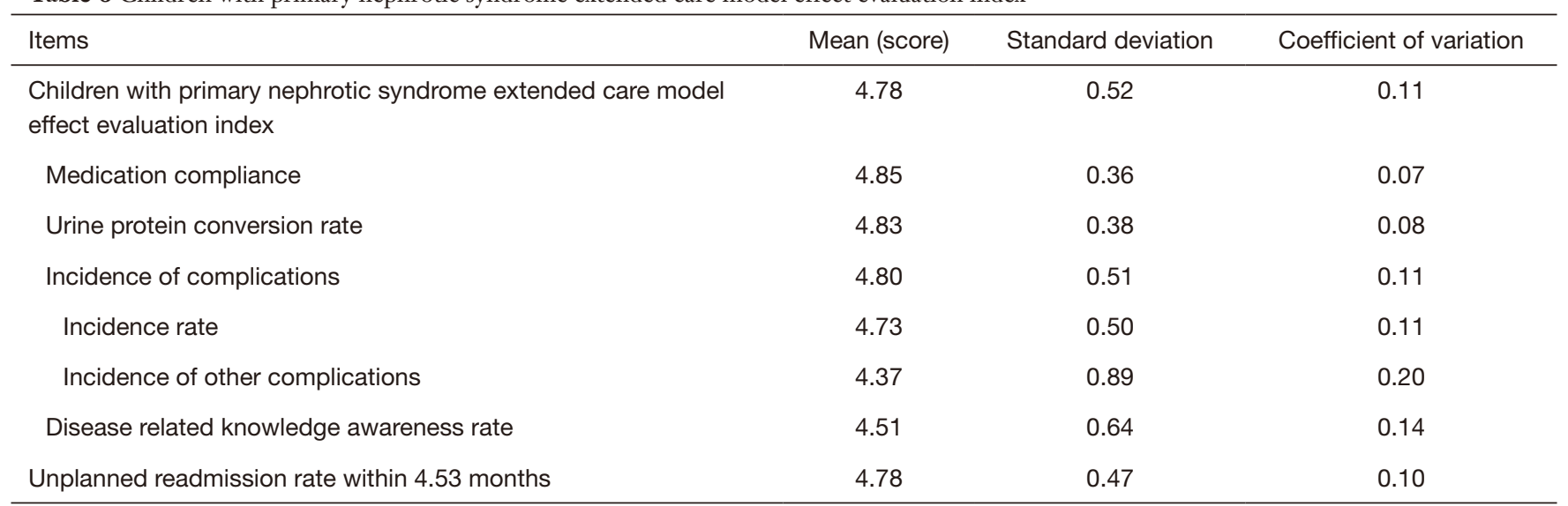

continuing care services in various hospitals and professional departments mostly have decentralized management. There are strong subjectivity problems in service objects, nursing contents, implementation methods, starting and ending time and other aspects, and there is no unified implementation standard and guidance of laws and regulations (19). In China, continuing care is mostly carried out by the primary nurse in the ward, and the implementation methods include on-site visits and telephone follow-ups (19). However, there is no normative model, and the goals, implementation processes, content and methods of continuing care lack of norms and standards (20).

The outline for the development plan of nursing in China [2006-2006] issued by the National Health and Family Planning Commission of the People's Republic of China noted that it is necessary to promote continuing care 
services and take advantage of the technical advantages of medical professionals in medical institutions. Implementing various types of continuing care after the patient is discharged from the hospital, expanding the field of nursing services to communities and families, and gradually improving continuing care methods and content ensures the continuity of care.

Based on the above background, the construction of a continuing care model for children with PNS responds to national policies, and meets the needs of social development. This can not only provide a mature, scientific and feasible continuing care model for children with PNS, but also provide reference for the management of chronic diseases in children and the whole population.

\section{Conclusions}

From the perspective of the professional medical staff, the present study clarified the procedures and work content of continuing care for children with PNS. However, there is a lack of survey on the needs of children and parents with PNS for continuing care.

Therefore, in follow-up studies, it is necessary to further explore the appropriate working procedures and contents of the community in carrying out the continuing care model for children with PNS, and evaluate the clinical effects of the proposed continuing care model for children with PNS. There is also a need to verify the effect of and improve the model, and verify the guarantee mechanism of the implementation of this model from the perspective of quality control, inspection standard, medical security policy, and price and fee system.

\section{Acknowledgments}

Funding: None.

\section{Footnote}

Reporting Checklist: The authors have completed the STROBE Reporting Checklist. Available at http://dx.doi. org/10.21037/apm-19-480

Data Sharing Statement: Available at http://dx.doi. org/10.21037/apm-19-480

Conflicts of Interest: All authors have completed the ICMJE uniform disclosure form (available at http://dx.doi. org/10.21037/apm-19-480). The authors have no conflicts of interest to declare.

Ethical Statement: The authors are accountable for all aspects of the work in ensuring that questions related to the accuracy or integrity of any part of the work are appropriately investigated and resolved. This study was conducted in accordance with the Declaration of Helsinki (as revised in 2013) and approved by the ethics committee of Biomedical Research Ethic Committee of Shandong Provincial Hospital (No. SWYX2020-044). All guardians had signed the informed consent.

Open Access Statement: This is an Open Access article distributed in accordance with the Creative Commons Attribution-NonCommercial-NoDerivs 4.0 International License (CC BY-NC-ND 4.0), which permits the noncommercial replication and distribution of the article with the strict proviso that no changes or edits are made and the original work is properly cited (including links to both the formal publication through the relevant DOI and the license). See: https://creativecommons.org/licenses/by-nc-nd/4.0/.

\section{References}

1. Yamamoto R, Imai E, Maruyama S, et al. Regional variations in immunosuppressive therapy in patients with primary nephrotic syndrome: the Japan nephrotic syndrome cohort study. Clin Exp Nephrol 2018;22:1266-80.

2. Downie ML, Gallibois C, Parekh RS, et al. Nephrotic syndrome in infants and children: pathophysiology and management. Paediatr Int Child Health 2017;37:248-58.

3. Linn AC, Caregnato RCA, Souza EN. Clinical simulation in nursing education in intensive therapy: an integrative review. Rev Bras Enferm 2019;72:1061-70.

4. van Walraven C, Oake N, Jennings A, et al. The association between continuity of care and outcomes: a systematic and critical review. J Eval Clin Pract 2010;16:947-56.

5. Martínez P, Rojas G, Martínez V, et al. Measuring Primary Health Care Clinicians' Skills for Depression Management. Front Psychiatry 2019;10:570.

6. Pourvakhshoori N, Norouzi K, Ahmadi F, et al. Nursing in disasters: A review of existing models. Int Emerg Nurs 2017;31:58-63.

7. Tang X, Pei X, Zhou L, et al. Research progress and enlightenment of family nursing quality evaluation index 
abroad. Chin J Nurs 2016;4:479-82.

8. Cheng W, Liu Y, Wang R, et al. The test for Kendall Coefficient of concordance $W$ conducted by SPSS. Journal of Taishan Medical College 2010;31:487-90.

9. Gonzci A. Competency based assessment in the professions in Australia. Assess Edu 1994;1:27-44.

10. Han S, Wen X, Lu L, et al. Construction of enterostomy hospital-community-home care model by Delphi method. Journal of Nursing Science 2013;28:7-9.

11. Chen Q, Lin R, Zhao H, et al. Application of Delphi method in the development of ICU body restraint scale. Qilu Nursing Journal 2016;22:85-7.

12. Humphrey-Murto S, Varpio L, Wood TJ, et al. The Use of the Delphi and Other Consensus Group Methods in Medical Education Research: A Review. Acad Med 2017;92:1491-8.

13. McPherson S, Reese C, Wendler MC. Methodology Update: Delphi Studies. Nurs Res 2018;67:404-10.

14. Xie F, Chen S, Cai W, et al. Establishment and practice of full-time jobs in the Continuing Nursing Service Department. Chinese Journal of Nursing 2013;48:47-9.

15. Klomstad K, Pedersen R, Førde R, et al. Involvement

Cite this article as: Li FX, Hou YL, Zhou LS, Dong Y, Zhao JW, Li ZX. The status and model of children primary nephrotic syndrome in continuing nursing. Ann Palliat Med 2021;10(3):2398-2407. doi: 10.21037/apm-19-480 in decisions about intravenous treatment for nursing home patients: nursing homes versus hospital wards. Bmc Medical Ethics 2018;19:34.

16. Cestari VR, Florêncio RS, Moreira TM, et al. Nursing competencies in promoting the health of individuals with chronic diseases. Rev Bras Enferm 2016;69:1195-203.

17. Holtschneider ME, Park CW. Simulation and Advanced Practice Registered Nurses: Opportunities to Enhance Interprofessional Collaboration. AACN Adv Crit Care Fall 2019;30:269-73.

18. Kilgore C. Development of a capability-based training programme for an advanced nurse practitioner. Nurs Older People 2019;31:22-7.

19. Bregar B, Skela-Savič B, Kores Plesničar B. Cross-sectional study on nurses' attitudes regarding coercive measures: the importance of socio-demographic characteristics, job satisfaction, and strategies for coping with stress. BMC Psychiatry 2018;18:171.

20. Zhai H, Sun G, Shao Y. Progress in continuation nursing of patients with chronic diseases. Journal of Nursing 2014;29:92-4. 